\title{
Condição de Ocupação e Informalidade no Mercado de Trabalho Brasileiro em 2007
}

\section{Labor Force Status and Informality in the Brazilian Labor Market in 2007}

\author{
Elvanio Costa de Souza* \\ João Eustáquio de Lima**
}

Resumo: Entre os problemas que afetam o mercado de trabalho brasileiro, a informalidade merece destaque, pois atinge cerca de $50 \%$ da população economicamente ativa. Este artigo procurou identificar quais fatores exercem maior influência sobre a condição de ocupação de um indivíduo brasileiro economicamente ativo de 16 anos ou mais de idade. Para tal, utilizaram-se as informações da Pesquisa Nacional por Amostra de Domicílios (PNAD) de 2007 e o modelo logit multinomial. A idade e a escolaridade têm efeito positivo sobre a probabilidade de uma pessoa conseguir um emprego, principalmente formal. Indivíduos do sexo masculino e indivíduos brancos ou amarelos têm mais chances de estar empregados, sobretudo formalmente. Aqueles que residem no meio rural têm menor probabilidade de estar desocupados. Morar nas regiões Nordeste e Norte aumenta a probabilidade de trabalhar informalmente.

Palavras-chave: Mercado de trabalho brasileiro. Informalidade. Modelo Logit Multinomial.

Abstract: The informality is an important problem affecting the Brazilian labor market, considering that around $50 \%$ of the economically active population is in the informal sector. We used the data from the 2007 Brazilian National Household Survey (PNAD) and the multinomial logit model to identify the factors with the greatest influence on the labor force status of an economically active person aged 16 years and over in Brazil. Age and education have a positive effect on the probability of an individual of getting employed, especially formal. Male individuals, as well as white or yellow individuals, are more likely to get employed, especially in the formal sector. Those who reside in rural areas are more likely to be employed. Living in Northeast and North Regions increases the probability of working informally.

Keywords: Brazilian labor market. Informality. Multinomial Logit Model.

JEL Classification: J83; J24.

Professor adjunto do Departamento de Economia da Universidade Federal de Viçosa. E-mail: elvanio.souza@ufv.br

* Professor titular do Departamento de Economia Rural da Universidade Federal de Viçosa. E-mail: jelima@ufv.br 


\section{Introdução}

Um estudo do Banco Mundial (Bird) aponta o elevado número de trabalhadores informais como um obstáculo ao desenvolvimento da América Latina e do Caribe, uma vez que a informalidade reduz o crescimento e "corrói a integridade" dasociedade (PERRY etal., 2007). Segundoesseestudo, ainformalidade na região é consequência de políticas inadequadas, de mecanismos de exclusão e de decisões de custo-benefício das empresas, bem como do descumprimento das funções de garantir segurança jurídica e econômica, igualdade de oportunidades e provisão adequada de bens públicos por parte dos governantes.

Um dos fenômenos mais marcantes entre as várias mudanças no funcionamento do mercado de trabalho brasileiro, a partir dos anos 1990, foi a proliferação das práticas informais, as quais normalmente são associadas à precarização da qualidade do trabalho, à fragilização da inserção no mercado e à banalização dos vínculos empregatícios (RAMOS, 2007).

A elevação do grau de informalidade observada a partir dos primeiros anos da década de 1990, tendência que se manteve ao longo de toda a década, é consequência tanto do crescimento da proporção de trabalhadores por conta própria, quanto dos sem carteira de trabalho assinada. O crescimento da informalidade nos anos 1990 foi muito maior do que o ocorrido no período de crise no início dos anos 1980 e, de acordo com Ulyssea (2005), esteve vinculado às mudanças na composição setorial da ocupação no mercado de trabalho urbano: significativa expansão do setor de serviços, tradicionalmente intensivo em postos de trabalho informais, e contração da indústria de transformação, setor mais intensivo em postos de trabalho formais. Além disso, ocorreu uma evolução da informalidade dentro desses mesmos setores.

Durante a década de 1990 e nos primeiros anos da década de 2000, o grau de informalidade no mercado de trabalho brasileiro, dado pela razão entre o número de pessoas ocupadas informalmente e o número total de pessoas ocupadas, girava em torno de $60 \%$. A partir de 2003, iniciou-se um processo de queda da informalidade, puxado pela dinâmica de crescimento econômico continuado em um quadro macroeconômico de relativo equilíbrio. Apesar da ligeira redução da informalidade no Brasil, ela ainda é bastante elevada. Conforme informações da Pesquisa Nacional por Amostra de Domicílios (INSTITUTO BRASILEIRO DE GEOGRAFIA E ESTATÍSTICA, 2007), o grau de informalidade foi de $54,1 \%$ em 2007. Entre as regióes brasileiras, o caso mais gritante é o da região Nordeste, na qual 70,5\% das pessoas ocupadas trabalhavam informalmente em 2007.

Alguns não veem na informalidade algo tão maléfico, na medida em que absorve contingentes de mão de obra menos qualificada que não encontram colocação no setor protegido, contribuindo, desse modo, para a redução do desemprego. Entretanto, não se deve esquecer que o setor informal é gerador de empregos de baixa qualidade e remuneração, ineficiências e custos econômicos adicionais, ou seja, gerador de distorção (RAMOS, 2007). 
Alguns estudos têm sido realizados abordando a questão da informalidade. Ulyssea (2005) buscou organizar e discutir de forma sistemática os principais trabalhos da literatura nacional e, em menor medida, internacional, referentes à informalidade no mercado de trabalho. Ramos e Ferreira (2006) examinaram a evolução da informalidade no mercado de trabalho brasileiro no período pósabertura comercial, destacando suas dimensões espacial e setorial.

Vaz (2006) analisou a evolução do mercado de trabalho metropolitano no período 1982-2002, a partir da perspectiva teórica da segmentação. Ele procurou avaliar o impacto das mudanças estruturais dos anos 1990 sobre o destino do trabalhador no mercado de trabalho e identificar quais foram os grupos de trabalhadores mais prejudicados nesse processo.

Curi e Menezes-Filho (2006) examinaram o comportamento do mercado de trabalho formal e informal no Brasil nas últimas duas décadas, utilizando dados longitudinais da Pesquisa Mensal de Emprego para seis regiões metropolitanas no Brasil. Machado, Oliveira e Antigo (2008) investigaram o diferencial de rendimentos entre os setores informal e formal no Brasil urbano nos anos 1992, 1998 e 2004.

Visando contribuir para um maior conhecimento a respeito da questão da informalidade no mercado de trabalho brasileiro, este artigo tem por objetivo identificar quais fatores exercem maior influência sobre a condição de ocupação de um indivíduo brasileiro economicamente ativo. Para tal, utilizamse as informações da PNAD de 2007 e o modelo logit multinomial.

$\mathrm{Na}$ medida em que a informalidade afeta de forma negativa o bem-estar da população e o processo de desenvolvimento econômico, torna-se importante conhecê-la melhor para poder combatê-la. Apesar da relevância do tema, relativamente pouco se tem estudado a seu respeito. Identificar quais fatores levam os indivíduos a trabalhar na informalidade e quantificar a importância de cada um desses fatores é relevante para a elaboração de políticas que visem reduzi-la.

$\mathrm{Na}$ segunda parte deste artigo, apresentam-se alguns conceitos concernentes à informalidade no mercado de trabalho. Na terceira parte, tratase da metodologia utilizada. Na quarta parte, apresentam-se e discutem-se os resultados. Na última parte, seguem as considerações finais.

\section{Informalidade no Mercado de Trabalho}

De acordo com Meneguin e Bugarin (2008), existem distintas definições sobre o que é o setor informal. Pela legislação brasileira, o setor informal engloba os trabalhadores não registrados, ou seja, aqueles que não possuem carteira de trabalho assinada e estão, desse modo, à margem de benefícios como repouso semanal remunerado, contribuição para a seguridade social, direito a requerer seguro-desemprego e a ter uma compensação financeira no caso de demissão sem justa causa e licença gestante e paternidade. A Organização Internacional do Trabalho (OIT) acrescenta ainda ao setor informal as pessoas sem 
remuneração e os autônomos. Além disso, há autores que preferem classificar como pertencentes ao setor informal os indivíduos não segurados pela previdência social.

Segundo Machado, Oliveira e Antigo (2008), além de haver várias definições para o setor informal, faz-se uma confusão entre relação de trabalho, atividade e setor. A definição mais utilizada associa a informalidade à regulamentação do trabalho e trata como informal os assalariados sem carteira de trabalho assinada. Na concepção da OIT, o setor informal abarca as atividades geradoras de renda relativamente baixa, as quais aglutinam os grupos de trabalhadores mais pobres no meio urbano. Essas atividades ocupam segmentos do mercado não preenchidos pela firma capitalista, dada a baixa lucratividade que inviabiliza sua operação. Esse enfoque de subordinação considera como pertencente ao setor informal a pequena unidade produtiva na qual o proprietário dos meios de produção não está separado do processo de trabalho. Envolve, portanto, as pequenas empresas familiares, o trabalhador autônomo (excluindo-se o profissional liberal) e o serviço doméstico remunerado em moeda ou espécie.

Segundo Dedecca e Baltar (1997), o surgimento do setor informal na América Latina está inserido no processo de modernização econômica implantado no pós-guerra. Os projetos nacionais de industrialização, baseados em fluxos de capitais estrangeiros, consolidaram um núcleo de atividade econômica moderna. No entanto, o setor agrícola tradicional e os pequenos e médios negócios urbanos ainda apresentavam elevado peso em termos de ocupação. Com isso, coexistiam setores com níveis elevados de produtividade e uma ampla gama de atividades de baixa eficiência, responsáveis pela ocupação de uma fração significativa da população economicamente ativa.

A desarticulação de formas tradicionais de produção, especialmente a agrícola, combinada com o elevado crescimento demográfico, gerou rápido processo migratório para as cidades. Como a capacidade de absorção dos segmentos modernos frente ao aumento da força de trabalho urbana era pequena, grandes parcelas da população ativa foram levadas a se manterem em ocupações de baixa produtividade, sem proteção social e negociação coletiva, como o comércio ambulante, os serviços de reparação e conservação domiciliar e o serviço doméstico. A ausência de uma tradição de trabalho assalariado da população migrante facilitou sua inserção direta no setor informal, na medida em que esta aceitava com facilidade qualquer ocupação que lhe gerasse alguma renda.

Com isso, passou-se a observar uma dualidade no mercado de trabalho: um setor moderno (ou formal), com elevada relação capital/trabalho, salários maiores, empregos mais estáveis, oportunidades de aprendizagem (programas de treinamento) e sistemas de promoção de carreira; e, um setor informal, com baixa produtividade do trabalho, salários menores, instabilidade e ausência de programas de treinamento e de sistemas de progressão de carreira (SOUZA, 1976; VAZ, 2006). 
De acordo com Dedecca e Baltar (1997), houve um novo impulso de crescimento do setor informal na América Latina a partir do final dos anos 1970. Dessa vez, a crise e os programas de liberalização econômica implantados por diversos países da região provocaram a desarticulação da estrutura industrial, gerando um forte fluxo de trabalhadores do segmento formal para o informal.

No Brasil, o processo de abertura da economia provocou um significativo crescimento da informalidade durante a década de 1990 (RAMOS; FERREIRA, 2006). Esse processo visava o enxugamento da estrutura produtiva, principalmente na indústria de transformação, com o objetivo de aumentar a competitividade externa dos produtos nacionais. Nesse processo de enxugamento das plantas industriais, a difusão da prática de "terceirização" contribuiu para o crescimento do setor de serviços. Além da realocação da mão de obra da indústria de transformação para o setor de serviços, esses autores apontam, como responsável pelo crescimento da informalidade na década passada, a sua elevação dentro do próprio setor industrial.

Segundo Ramos (2007), as firmas são motivadas a atuar na informalidade como um modo de redução de custos e aumento, ou manutenção, das margens de lucros, por meio do não recolhimento de encargos trabalhistas e contribuição previdenciária. A informalidade permite que firmas menos produtivas permaneçam no mercado, dificultando, com isso, a expansão de firmas mais produtivas que respeitam a legislação e que, consequentemente, apresentam maiores custos de produção. Além disso, um maior grau de informalização reduz a base para taxação, o que leva ao aumento dos tributos, criando maior penalização para as firmas mais produtivas e gerando incentivos para o incremento da própria informalidade.

O incentivo à informalidade, do ponto de vista das firmas, deve ser tanto maior quanto menor o seu tamanho - firmas maiores são mais visíveis para fins de fiscalização e tendem a apresentar redução dos custos do fator trabalho em termos relativos -, menos qualificada a mão de obra demandada e pior o desempenho da economia.

Para os trabalhadores assalariados, é lícito admitir uma preferência pelos empregos formais, partindo-se da premissa de que são, de fato, de melhor qualidade e remuneração. Entretanto, possuir um emprego formal não é simplesmente uma questão de escolha. Conforme Vaz (2006), há mais pessoas querendo emprego do que emprego sendo ofertado no setor formal. Além disso, existem barreiras à entrada nos setores que pagam os melhores salários, como necessidade de conhecimentos específicos do setor (com experiência comprovada em carteira, por exemplo) e custos de qualificação (maiores requerimentos de escolaridade, entre outros). Desse modo, a opção pela informalidade, no caso dos trabalhadores assalariados, seria dada, de um modo geral, por uma impossibilidade de adentrar no setor formal. 
Para a outra classe de trabalhadores informais, os trabalhadores por conta própria (ou autônomos), a informalidade proporciona oportunidade de fuga da taxação como forma de viabilizar ocupações de baixa produtividade (RAMOS, 2007). Diferente dos trabalhadores assalariados sem carteira, muitos trabalhadores por conta própria preferem esse tipo de ocupação ao trabalho assalariado com carteira, dada a escassez de empregos condizentes com suas características (conhecimentos e habilidades) ou mesmo a possibilidade de auferir salários maiores do que aqueles que seriam recebidos se fossem empregados com carteira (VAZ, 2006).

\section{Metodologia}

Objetiva-se, neste artigo, verificar como algumas características, tais como idade, escolaridade, sexo, cor e local de residência, influenciam na probabilidade de um indivíduo se encontrar em uma das três situações: desocupado, ocupado informalmente ou ocupado formalmente.

Um indivíduo, ao escolher uma de duas ou mais alternativas disponíveis, toma como base a utilidade que esta representa para ele. De acordo com Greene (2008), a utilidade da alternativa j para o i-ésimo indivíduo que se depara com $m$ alternativas é

$$
U_{i j}=x_{i j}{ }^{\prime} \beta_{i}+\varepsilon_{i j}
$$

em que $x_{i j}$ são as variáveis que influenciam na escolha da alternativa j e $\beta_{1}$ são os parâmetros associados a essas variáveis.

Os modelos econométricos nos quais a variável dependente indica uma escolha discreta entre $m$ categorias mutuamente exclusivas são denominados modelos de resultado discreto ou de resposta qualitativa (CAMERON; TRIVEDI, 2005). Neste artigo, são três as alternativas disponíveis ao indivíduo $(m=3)$, a escolha de uma delas depende apenas das características do próprio indivíduo, e elas são não ordenadas. Nesse caso, o modelo adequado é o logit multinomial.

A probabilidade de o indivíduo $i$ escolher a j-ésima de $m$ alternativas é dada por

$$
p_{i j}=\operatorname{Pr}\left[y_{i}=j\right]=F_{j}\left(x_{i}, \beta\right), \quad j=1, \ldots, \mathrm{m}, \quad i=1, \ldots, \mathrm{N},
$$

em que $x_{i}$ são variáveis explicativas e $\beta$ são parâmetros.

Diferentes especificações funcionais para $F_{j}$ correspondem a diferentes modelos multinomiais. A forma funcional de $F_{j}$ deve ser tal que as probabilidades se situem entre zero e um e a soma delas seja um. 
No modelo logit multinomial, especificamente, a probabilidade de o i-ésimo indivíduo escolher a j-ésima de $m$ alternativas é dada por

$$
p_{i j}=\frac{e^{x_{i}^{\prime} \beta_{j}}}{\sum_{l=1}^{m} e^{x_{i}^{\prime} \beta_{l}}}, \quad \mathrm{j}=1, \ldots, \mathrm{m}, \quad \mathrm{i}=1, \ldots, \mathrm{N},
$$

em que $x_{i}{ }^{\prime}=\left[\begin{array}{lllll}1 & x_{i 2} & x_{i 3} & \cdots & x_{i k}\end{array}\right]$ é um vetor de ordem $1 \times k$ das variáveis explicativas (características do indivíduo $i$ ), sendo que o primeiro elemento é unitário; e, $\beta_{j}=\left[\begin{array}{llll}\beta_{j 1} & \beta_{j 2} & \cdots & \beta_{k}\end{array}\right]^{\prime}$ é um vetor de coeficientes de ordem $k \times 1$ associado à j-ésima alternativa.

Neste trabalho, a variável dependente $\left(y_{i}\right)$ assume os seguintes valores:

$y_{i}= \begin{cases}1 & \text { se o indivíduo está desocup ado } \\ 2 & \text { se o indivíduo está ocupado informalmente } \\ 3 & \text { se o indivíduo está ocupado formalmente }\end{cases}$

Assim, a probabilidade de o i-ésimo indivíduo escolher a j-ésima alternativa é

$$
p_{i j}=\operatorname{Pr}\left[y_{i}=j\right]=\frac{e^{x_{i}{ }^{\prime} \beta_{j}}}{\sum_{l=1}^{3} e^{x_{i}{ }^{\prime} \beta_{l}}}, \quad \mathrm{j}=1,2,3, \quad \mathrm{i}=1, \ldots, \mathrm{N} .
$$

Entretanto, como a soma das probabilidades de escolha das $m$ alternativas pelo indivíduo $i$ deve ser um, $\sum_{j=1}^{m} p_{i j}=1$, uma restrição é necessária para assegurar a identificação do modelo. A restrição usual é a normalização da categoria base, ou de referência, que consiste em fazer os coeficientes associados a ela iguais a zero. Neste artigo, a categoria escolhida como referência é $j=1$ (desocupado). Portanto faz-se o vetor $\beta_{1}=0$.

Fazendo-se $\beta_{1}=0$, tem-se que $e^{x_{i}{ }^{\prime} \beta_{1}}=1$. Desse modo, a probabilidade condicional de o $i$-ésimo indivíduo escolher a j-ésima alternativa, dado que a alternativa $j=1$ é observada, é:

$$
p_{i j}=\operatorname{Pr}\left[y_{i}=j\right]=\frac{e^{x_{i}^{\prime} \beta_{j}}}{1+\sum_{l=2}^{3} e^{x_{i}^{\prime} \beta_{l}}}, \quad \mathrm{j}=2,3, \quad \mathrm{i}=1, \ldots, \mathrm{N} .
$$


Da mesma forma, a probabilidade condicional de o i-ésimo indivíduo escolher a alternativa $j=1$ é:

$$
p_{i 1}=\operatorname{Pr}\left[y_{i}=1\right]=\frac{1}{1+\sum_{l=2}^{3} e^{x_{i} \beta_{l}}}, \quad \mathrm{j}=2,3, \quad \mathrm{i}=1, \ldots, \mathrm{N} .
$$

Por causa da normalização, as estimativas referem-se à razão entre a probabilidade de o indivíduo escolher a alternativa 2 (ocupar-se informalmente), ou a alternativa 3 (ocupar-se formalmente), e a probabilidade de ele escolher a alternativa 1 (permanecer desocupado).

Como os dados nos modelos multinomiais têm distribuição multinomial, a estimativa dos parâmetros deve ser feita por máxima verossimilhança. Os parâmetros estimados, no entanto, não são de fácil interpretação, visto que não denotam, de forma direta, as respostas marginais das variáveis explicativas sobre a variável dependente. Por esse motivo, calculam-se os efeitos marginais para facilitar a análise dos resultados. O efeito marginal da variável explicativa $x_{i k}$ é obtido por:

$$
\frac{\partial p_{i j}}{\partial x_{i k}}=p_{i j}\left[\frac{\partial\left(x_{i}^{\prime} \beta_{j}\right)}{\partial x_{i k}}-\sum_{l=2}^{3} P_{i l} \frac{\partial\left(x_{i}^{\prime} \beta_{l}\right)}{\partial x_{i k}}\right], \quad \mathrm{j}=2,3, \quad \mathrm{i}=1, \ldots, \mathrm{N} .
$$

Para variáveis explicativas contínuas, o efeito marginal representa o impacto de uma variação em uma unidade na variável explicativa sobre a probabilidade de o i-ésimo indivíduo escolher a j-ésima alternativa, dado que as demais variáveis independentes permaneçam em seus valores médios. Para variáveis explicativas discretas (qualitativas), ele informa qual a variação da probabilidade de escolha da alternativa $j$ pelo indivíduo i se a variável passa do valor zero (ausência da característica) para o valor um (presença da característica). Devese ressaltar que os efeitos marginais não possuem, necessariamente, o mesmo sinal dos coeficientes estimados.

Como dito anteriormente, a probabilidade de o i-ésimo indivíduo escolher a j-ésima alternativa é afetada pelas características desse indivíduo (variáveis explicativas). Para explicar a probabilidade de o indivíduo estar desocupado, ocupado informalmente ou ocupado formalmente, utilizaram-se as seguintes variáveis:

- Idade: idade do indivíduo, em anos.

- Idade2: idade do indivíduo, em anos, elevada ao quadrado.

- Escol: anos de estudo do indivíduo.

- Sexo: variável dummy que assume valor 1 se o indivíduo é do sexo feminino.

- Cor: variável dummy que assume valor 1 se o indivíduo é de cor branca ou amarela. 
- S: variável dummy que assume valor 1 se o indivíduo reside na região Sul.

- NE: variável dummy que assume valor 1 se o indivíduo reside na região Nordeste.

- CO: variável dummy que assume valor 1 se o indivíduo reside na região Centro-Oeste.

- $N$ : variável dummy que assume valor 1 se o indivíduo reside na região Norte.

- Rural: variável dummy que assume valor 1 se o indivíduo reside na zona rural.

Dada a falta de consenso a respeito da definição de setor informal, estimaram-se quatro modelos diferentes. Essa estratégia serve, também, para avaliar a robustez dos resultados. No primeiro modelo, deu-se mais ênfase à questão da subordinação, classificando-se como formais, principalmente, os trabalhadores ocupados em atividades tipicamente capitalistas. Assim, consideram-se como ocupados informalmente os empregados sem carteira assinada, os trabalhadores por conta própria, os trabalhadores para o próprio consumo, os trabalhadores na construção para o próprio uso e os não remunerados. Por outro lado, os empregados com carteira assinada, os militares, os funcionários públicos estatutários e os empregadores foram classificados como ocupados formalmente. Essa classificação de informalidade mais abrangente é utilizada, por exemplo, pelo Instituto de Pesquisa Econômica Aplicada - IPEA (2008).

No segundo modelo, excluíram-se da categoria ocupados informalmente os trabalhadores por conta própria urbanos que contribuem para a previdência. Isso visou, entre outros, retirar do setor informal aqueles trabalhadores que são autônomos por opção, ou seja, que não gostariam de ser assalariados com carteira assinada, em razão da escassez de empregos condizentes com suas características, da flexibilidade da jornada de trabalho, da independência de uma hierarquia, ou mesmo da possibilidade de auferir maiores rendimentos. Esse é o caso dos profissionais liberais, por exemplo. De acordo com a PNAD (INSTITUTO BRASILEIRO DE GEOGRAFIA E ESTATÍSTICA, 2007), os autônomos urbanos representam 16,8\% do total de ocupados. Entre eles, 18,6\% contribuem para a previdência.

O terceiro modelo foca mais a questão da proteção ao trabalhador. Assim, consideraram-se como formais todos os trabalhadores segurados da previdência, incluindo, além dos empregados com carteira assinada, militares, funcionários públicos estatutários e empregadores, os empregados sem carteira assinada, os trabalhadores por conta-própria, os que produzem para o próprio consumo, os trabalhadores na construção para o próprio uso e os não remunerados, desde que contribuam para a previdência. Além disso, excluíram-se da condição de informais os trabalhadores por conta própria, os que produzem para o próprio consumo, os trabalhadores na construção para o próprio uso e os não 
remunerados que residem no meio rural, uma vez que estes são segurados especiais da previdência. Por último, no quarto modelo, excluíram-se os trabalhadores que residem no meio rural da amostra. As estimativas, portanto, dizem respeito apenas aos trabalhadores urbanos. Isso porque as relações de trabalho e autoprodução rurais são muito díspares das do setor urbano. No meio rural, por exemplo, os trabalhadores por conta própria, os que produzem para o próprio consumo e os não remunerados representam $59,6 \%$ do total dos ocupados, enquanto que no setor urbano representam $24,1 \%$. Assim como no terceiro modelo, consideraram-se como formais todos os trabalhadores segurados da previdência.

\subsection{Fonte dos Dados}

Utilizaram-se os dados da Pesquisa Nacional por Amostra de Domicílios de 2007 (INSTITUTO BRASILEIRO DE GEOGRAFIA E ESTATÍSTICA, 2007). No banco de dados da PNAD, a variável "Condição de ocupação na semana de referência para pessoas de 10 anos ou mais de idade" apresenta-se subdividida em duas categorias: "ocupadas" e "desocupadas". Para cumprir os objetivos deste estudo, portanto, a categoria "ocupadas" precisou ser desagregada em duas novas categorias: "ocupadas informalmente" e "ocupadas formalmente". Essa desagregação foi efetuada com base nas categorias da variável "Posição na ocupação no trabalho principal da semana de referência para pessoas de 10 anos ou mais de idade".

Utilizaram-se apenas as pessoas da amostra com idade igual ou superior a 16 anos, visto que as menores de 16 anos são classificadas somente como desocupadas ou ocupadas informalmente, por conta da legislação trabalhista brasileira. Assim, não haveria indivíduos na categoria ocupados formalmente para essa faixa etária.

Ressalta-se, ainda, a atenção dada ao plano amostral da PNAD no momento da extração dos dados e da estimação dos modelos. O plano amostral da PNAD possui certas características que o definem como um "plano amostral complexo": estratificação das unidades de amostragem, conglomeração, probabilidades desiguais de seleção em um ou mais estágios e ajustes dos pesos amostrais para calibração com totais populacionais conhecidos (SILVA; PESSOA; LILA, 2002).

As estimativas de variância, desvio-padrão e parâmetros de alguns modelos sofrem a influência conjunta da estratificação, conglomeração e pesos. Com isso, as técnicas e sistemas de análise tradicionais, ao ignorar esses aspectos, podem produzir resultados incorretos tanto para as estimativas pontuais como para os respectivos desvios-padrão e níveis de significância, podendo comprometer a qualidade do ajuste dos modelos e a interpretação dos resultados. Isso ocorre porque os pacotes estatísticos baseiam-se em hipóteses válidas somente quando os dados são obtidos por meio de amostras aleatórias simples com reposição.

Neste artigo, para um tratamento correto dos dados, considerou-se o fator de expansão (peso) e o plano amostral da PNAD. Utilizou-se o software Stata 10.1 e variância dos coeficientes foi estimada pelo Método de Linearização de Taylor. 


\section{Resultados e Discussão}

O desemprego e a informalidade não se distribuem de forma homogênea no território brasileiro. Conforme pode ser visto na Tabela 1, a região Sudeste apresentou o maior percentual de pessoas desocupadas em 2007 (8,7\% da população economicamente ativa de 16 anos ou mais de idade), ao passo que a região Sul apresentou o menor percentual (5,6\%). As regiões Norte e Nordeste possuíam o maior percentual de pessoas trabalhando informalmente $(60,2 \%$ e 63,4\%, respectivamente). O Sudeste é a região com o maior percentual de pessoas ocupadas no setor formal $(51,7 \%){ }^{1}$

Tabela 1 - Percentual de pessoas de 16 anos ou mais de idade, economicamente ativas, por Grandes Regiões, segundo a condição de ocupação (2007).

\begin{tabular}{l|c|c|c|c|c|c}
\hline Condição de ocupação & Sul & Sudeste & Nordeste & Centro-Oeste & Norte & Brasil \\
\hline Desocupado & 5,6 & 8,7 & 8,3 & 7,7 & 7,7 & 8,0 \\
Ocupado informalmente & 45,7 & 39,5 & 63,4 & 46,9 & 60,2 & 48,7 \\
Ocupado formalmente & 48,7 & 51,7 & 28,2 & 45,4 & 32,1 & 43,3 \\
\hline
\end{tabular}

Fonte: Elaborada pelos autores a partir dos dados da PNAD (INSTITUTO BRASILEIRO DE GEOGRAFIA E ESTATÍSTICA, 2007).

A desocupação entre as mulheres (10,7\%) é quase o dobro da observada entre os homens $(5,9 \%)$, conforme pode ser observado na Tabela 2. Além disso, o percentual de homens que trabalham em ocupações formais $(45,8 \%)$ supera o percentual de mulheres $(40,1 \%)$. Em parte, esse menor percentual de mulheres ocupadas formalmente pode ser explicado pela diferença de atividades exercidas no mercado de trabalho. Em comparação com os homens, há uma menor participação das mulheres na indústria de transformação, onde a formalidade é maior $(65,3 \%)$, e um predomínio de mulheres nos serviços domésticos, onde a informalidade atinge $72 \%$ dos trabalhadores.

Tabela 2 - Percentual de pessoas de 16 anos ou mais de idade, economicamente ativas, por sexo, segundo a condição de ocupação (2007).

\begin{tabular}{l|c|c|c}
\hline Condição de ocupação & Homens & Mulheres & Total \\
\hline Desocupado & 5,9 & 10,7 & 8,0 \\
Ocupado informalmente & 48,3 & 49,2 & 48,7 \\
Ocupado formalmente & 45,8 & 40,1 & 43,3 \\
\hline
\end{tabular}

Fonte: Elaborada pelos autores a partir dos dados da PNAD (INSTITUTO BRASILEIRO DE GEOGRAFIA E ESTATÍSTICA, 2007).

1 Nas Tabelas 1 a 6, as pessoas são classificadas como ocupadas informalmente com base no conceito mais abrangente. Assim, consideram-se como trabalhadores informais os empregados sem carteira assinada, os trabalhadores por conta própria, os trabalhadores para o próprio consumo, os trabalhadores na construção para o próprio uso e os trabalhadores não remunerados. 
O percentual de desocupados é maior entre as pessoas mais jovens, conforme a Tabela 3. Das pessoas com idade entre 16 e 19 anos, 21,6\% encontravam-se desocupadas em 2007. Esse percentual diminui nos grupos de maior idade, até atingir $2 \%$ entre as pessoas com 60 anos ou mais. Isso mostra a preferência que existe no mercado de trabalho por pessoas com maior nível de experiência. Os dados também revelam que a informalidade é maior entre as pessoas mais jovens e as mais velhas. No caso dos mais jovens, grande parcela trabalha em micro e pequenas empresas, onde a informalidade é maior. O grupo com maior percentual de pessoas ocupadas formalmente é o de 30 a 39 anos de idade (49,6\%).

Tabela 3 - Percentual de pessoas de 16 anos ou mais de idade, economicamente ativas, por grupos de idade, segundo a condição de ocupação (2007).

\begin{tabular}{lc|c|c|c|c|c|c|c}
\hline $\begin{array}{c}\text { Condição de } \\
\text { ocupação }\end{array}$ & $\mathbf{1 6}$ a 19 & $\mathbf{2 0}$ a 29 & $\mathbf{3 0}$ a 39 & $\mathbf{4 0}$ a 49 & $\mathbf{5 0}$ a 59 & $\begin{array}{c}\mathbf{6 0} \text { ou } \\
\text { mais }\end{array}$ & Total \\
\hline Desocupado & 21,6 & 11,5 & 6,3 & 4,6 & 3,4 & 2,0 & 8,0 \\
Ocupado informalmente & 57,8 & 40,9 & 44,1 & 47,5 & 56,3 & 77,7 & 48,7 \\
Ocupado formalmente & 20,6 & 47,6 & 49,6 & 47,8 & 40,3 & 20,3 & 43,3 \\
\hline
\end{tabular}

Fonte: Elaborada pelos autores a partir dos dados da PNAD (INSTITUTO BRASILEIRO DE GEOGRAFIA E ESTATÍSTICA, 2007).

A Tabela 4 mostra a relação entre escolaridade e condição de ocupação. Observa-se que o maior percentual de pessoas desocupadas ocorre no grupo de 8 a 11 anos de estudo (11,6\%). A informalidade é maior entre as pessoas menos escolarizadas, atingindo $76,9 \%$ das pessoas com 3 anos ou menos de estudo. Por outro lado, no grupo de pessoas com 12 anos ou mais de estudo, $61,1 \%$ trabalham no mercado formal.

Tabela 4 - Percentual de pessoas de 16 anos ou mais de idade, economicamente ativas, por grupos de anos de estudo, segundo a condição de ocupação (2007).

\begin{tabular}{l|c|c|c|c|c}
\hline Condição de ocupação & $\mathbf{0 ~ a ~ 3}$ & $\mathbf{4}$ a 7 & $\mathbf{8}$ a 1 1 & 12 ou mais & Total \\
\hline Desocupado & 4,2 & 6,2 & 11,6 & 8,3 & 8,0 \\
Ocupado informalmente & 76,9 & 62,8 & 49,7 & 30,6 & 48,7 \\
Ocupado formalmente & 18,9 & 31,0 & 38,7 & 61,1 & 43,3 \\
\hline
\end{tabular}

Fonte: Elaborada pelos autores a partir dos dados da PNAD (INSTITUTO BRASILEIRO DE GEOGRAFIA E ESTATÍSTICA, 2007).

A desocupação é menor entre os brancos e amarelos (7,1\% e 7,7\%, respectivamente) e maior entre os negros (9,8\%), como pode ser visto na Tabela 5. Os maiores percentuais de pessoas ocupadas informalmente estão entre os indígenas $(55,5 \%)$ e pardos $(55,1 \%)$. Os brancos e amarelos possuem os maiores percentuais de ocupação formal (49,2\% e 47\%, respectivamente). A maior informalidade entre indígenas, negros e pardos se explica, em parte, pelo menor nível de escolaridade. Conforme os dados da PNAD de 2007, o percentual de indígenas, negros e pardos com até 3 anos de estudo é superior a 
$22 \%$, enquanto entre os brancos e amarelos fica abaixo de $13 \%$. Do mesmo modo, $43,1 \%$ dos brancos e $51,9 \%$ dos amarelos possuem 12 anos ou mais de estudo. Entre os indígenas, negros e pardos, esse percentual situa-se abaixo de 30\%.

Tabela 5 - Percentual de pessoas de 16 anos ou mais de idade, economicamente ativas, por cor, segundo a condição de ocupação (2007).

\begin{tabular}{lccccc|c|c|c}
\hline Condição de ocupação & Indígena & Branca & Preta & Amarela & Parda & Total \\
\hline Desocupado & 9,0 & 7,1 & 9,8 & 7,7 & 8,7 & 8,0 \\
Ocupado informalmente & 55,5 & 43,7 & 47,5 & 45,3 & 55,1 & 48,7 \\
Ocupado formalmente & 35,5 & 49,2 & 42,7 & 47,0 & 36,2 & 43,3 \\
\hline
\end{tabular}

Fonte: Elaborada pelos autores a partir dos dados da PNAD (INSTITUTO BRASILEIRO DE GEOGRAFIA E ESTATÍSTICA, 2007).

Apenas 2,9\% das pessoas que residiam no meio rural estavam na condição de desocupadas em 2007, contra $9 \%$ das que habitavam o meio urbano, conforme a Tabela 6. Por outro lado, o percentual de pessoas trabalhando informalmente no meio rural $(78,8 \%)$ é bem maior do que o do meio urbano $(42,7 \%)$. Esses dados parecem indicar que o meio rural oferece mais oportunidades de trabalho do que o meio urbano. Entretanto, em certa medida, a menor taxa de desocupação no meio rural é reflexo processo de mecanização ocorrido nos últimos anos (STADUTO; SHIKIDA; BACHA, 2004). Nesse aspecto, o menor nível de desemprego no meio rural não é reflexo de uma demanda por trabalho aquecida, mas de uma retração da oferta de trabalho por conta da saída intensa de trabalhadores do campo em virtude da mecanização. Como consequência, o êxodo rural tem provocado um aumento da taxa de urbanização no Brasil e, possivelmente, contribuído para um maior nível de desemprego no meio urbano.

Tabela 6 - Percentual de pessoas de 16 anos ou mais de idade, economicamente ativas, por situação do domicílio, segundo a condição de ocupação (2007).

\begin{tabular}{l|c|c|c}
\hline $\begin{array}{c}\text { Situação do } \\
\text { domicílio }\end{array}$ & Desocupado & $\begin{array}{c}\text { Ocupado } \\
\text { informalmente }\end{array}$ & Ocupado formalmente \\
\hline Urbana & 9,0 & 42,7 & 48,3 \\
Rural & 2,9 & 78,8 & 18,2 \\
\hline
\end{tabular}

Fonte: Elaborada pelos autores a partir dos dados da PNAD (INSTITUTO BRASILEIRO DE GEOGRAFIA E ESTATÍSTICA, 2007).

A Tabela 7 apresenta os coeficientes estimados por meio do modelo logit multinomial para as condições de ocupação dos indivíduos brasileiros economicamente ativos de 16 anos ou mais de idade. Os resultados são reportados para os quatro modelos estimados, cada qual baseado em um diferente conceito de ocupação formal/informal. A estatística $F$ dos modelos variou de 708,99 (modelo C) a 848,95 (modelo D), todas significativas ao nível de $1 \%$, indicando que os coeficientes das variáveis explicativas, em conjunto, não são iguais a zero. 
Os coeficientes estimados foram, em sua maioria, estatisticamente diferentes de zero ao nível de 1\% de significância. Eles apresentam os sinais esperados: maior escolaridade aumenta as chances de uma pessoa conseguir uma ocupação formal e reduz as de se ocupar informalmente; mulheres têm menor probabilidade de conseguir uma ocupação, sobretudo formal; indivíduos brancos e amarelos têm mais chances de estar ocupados; em relação às pessoas que moram no Sudeste, aquelas que residem nas regiões Sul, Nordeste, CentroOeste e Norte têm maior probabilidade de se ocupar informalmente; morar nas regiões Nordeste e Norte diminui as chances de o indivíduo conseguir uma ocupação formal. Em três dos quatro modelos, apenas os indivíduos que moram no Sul têm maior probabilidade de conseguir uma ocupação formal em relação aos que residem no Sudeste. De acordo com os modelos A e B, residir no meio rural aumenta a probabilidade de o indivíduo conseguir uma ocupação, sobretudo informal. No modelo C, no qual os trabalhadores rurais autônomos, os que produzem para o próprio consumo e os não remunerados foram retirados da categoria "ocupados informalmente", residir no meio rural aumenta as chances de uma pessoa estar ocupada, porém, apenas no setor formal. 


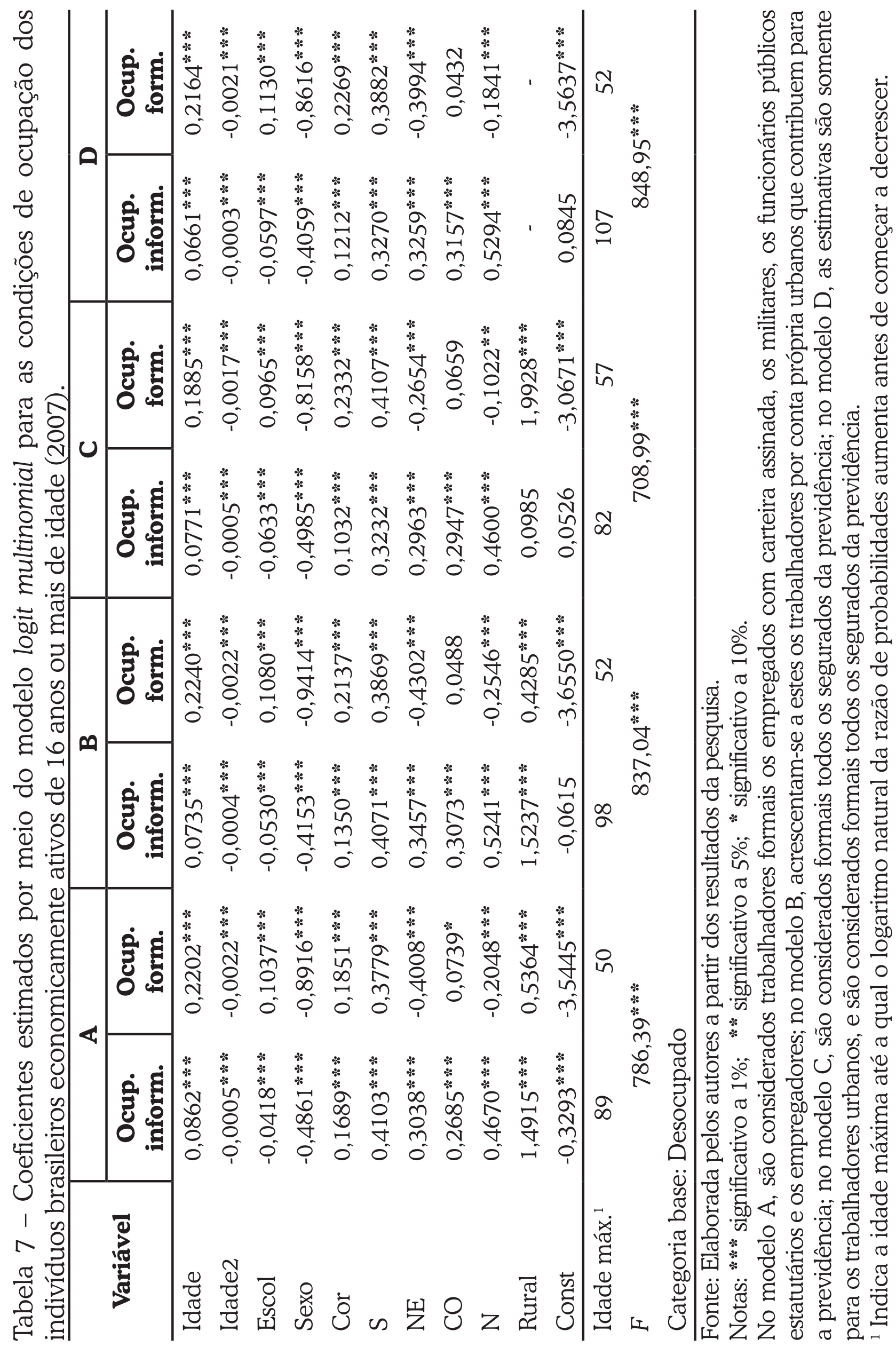


Os sinais dos coeficientes da variável Idade são positivos, indicando que à medida que o indivíduo fica mais velho a probabilidade de estar ocupado aumenta relativo à de estar desocupado. Entretanto, essa probabilidade não cresce infinitamente com a idade. $\mathrm{O}$ coeficiente negativo da variável Idade 2 (idade ao quadrado) mostra que as chances de o indivíduo conseguir um emprego aumentam até certa idade e depois passam a decrescer. Os resultados do modelo A, por exemplo, revelam que as chances de o indivíduo conseguir uma ocupação informal crescem até os 89 anos de idade e, as de se ocupar formalmente, até os 50 anos. Com isso, conclui-se que os indivíduos mais jovens têm menores chances de conseguir um emprego do que os mais velhos e que tanto os mais jovens como aqueles com mais de 50 anos têm menor probabilidade de encontrar uma ocupação formal. Como a análise dos efeitos marginais é mais simples do que a dos coeficientes, os demais coeficientes não serão analisados. ${ }^{2} \mathrm{~A}$ análise a seguir se limita aos efeitos marginais.

A Tabela 8 apresenta os efeitos marginais das variáveis explicativas das condições de ocupação dos indivíduos brasileiros. Os efeitos marginais não apresentam, necessariamente, os mesmos sinais dos coeficientes. Em relação ao modelo A, que classifica os trabalhadores ocupados como formais ou informais com base no conceito de subordinação, os efeitos marginais de algumas variáveis explicativas não são estatisticamente diferentes de zero, implicando que elas não influenciam a condição de ocupação. Com isso, infere-se que: as pessoas que residem na região Nordeste têm, em média, a mesma probabilidade estar desocupadas do que as que moram no Sudeste; a idade e a cor não afetam a probabilidade de as pessoas se ocuparem informalmente; e, os indivíduos que moram na região Sul têm, em média, a mesma probabilidade de conseguir um emprego formal do que os que residem na região Sudeste.

Os coeficientes estimados pelo modelo logit multinomial representam o efeito de uma variação em uma unidade na variável explicativa $x_{k}$ sobre o logaritmo natural da razão de probabilidades - a razão entre a probabilidade de o indivíduo se encontrar Ocupado informalmente (ou Ocupado formalmente) e a probabilidade de estar Desocupado (a categoria base) -, no caso de variáveis explicativas contínuas. Para variáveis explicativas qualitativas, o coeficiente reflete o impacto de possuir determinado atributo sobre o logaritmo natural da razão de probabilidades. Desse modo, se o coeficiente é positivo (razão de probabilidades maior do que um), as chances de o indivíduo estar ocupado (formalmente ou informalmente) aumentam quando o valor da variável explicativa aumenta, se ela for contínua, ou se ela passa de zero para um, no caso de ser discreta. Se o coeficiente é negativo (razão de probabilidades menor que um), as chances de estar ocupado diminuem com o aumento do valor da variável explicativa associada ao coeficiente. 
อุด

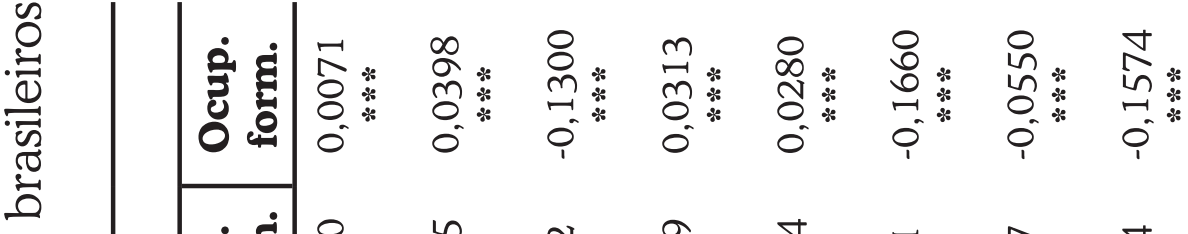

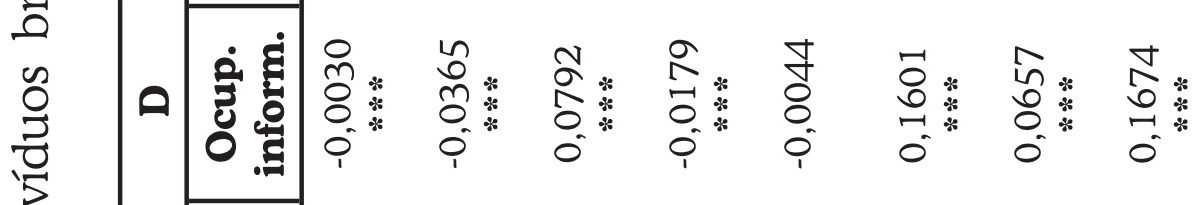

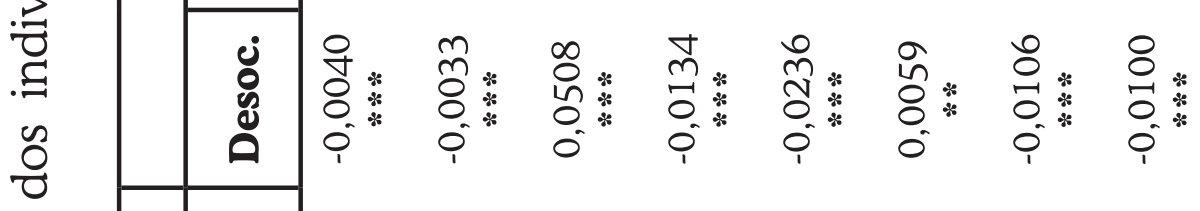

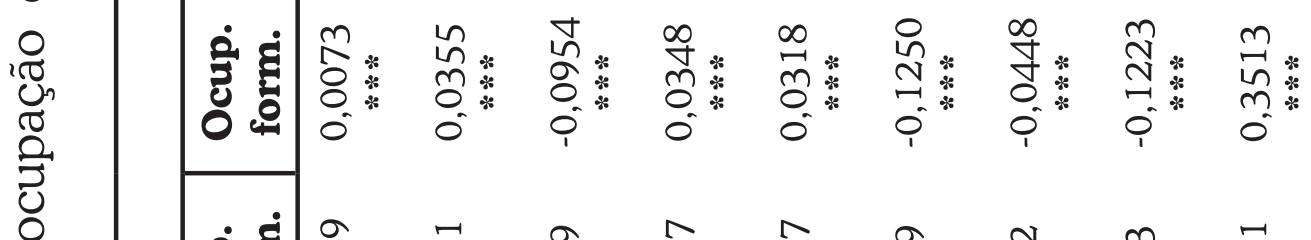

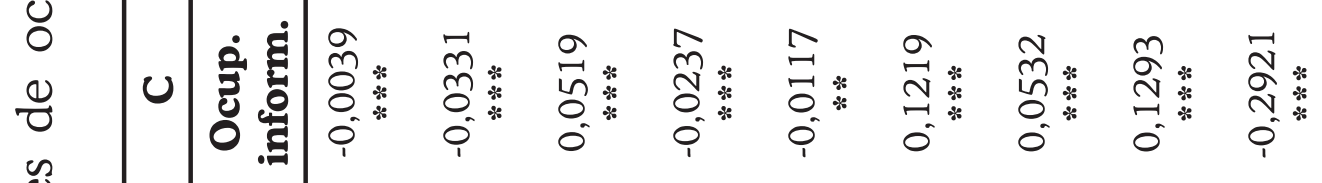

ఖ

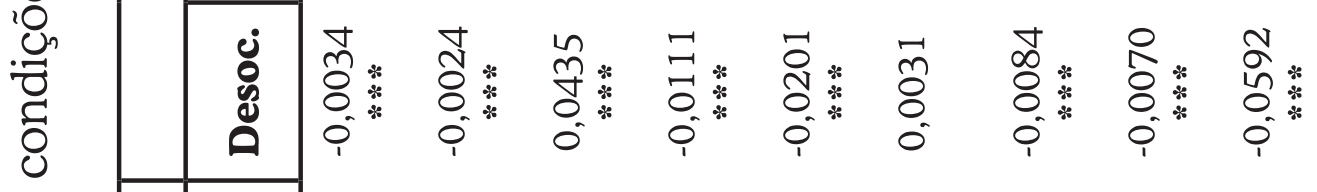

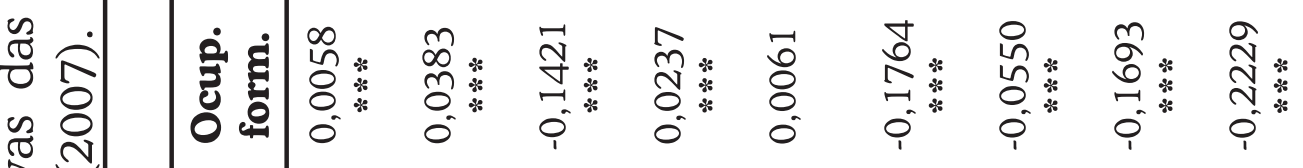

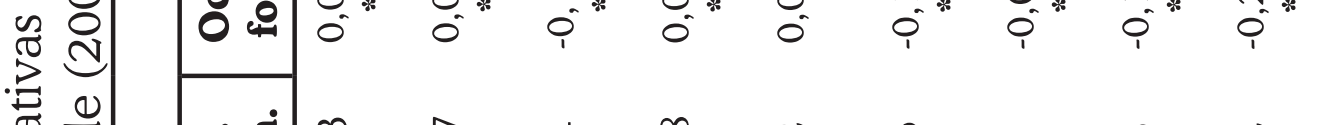

导

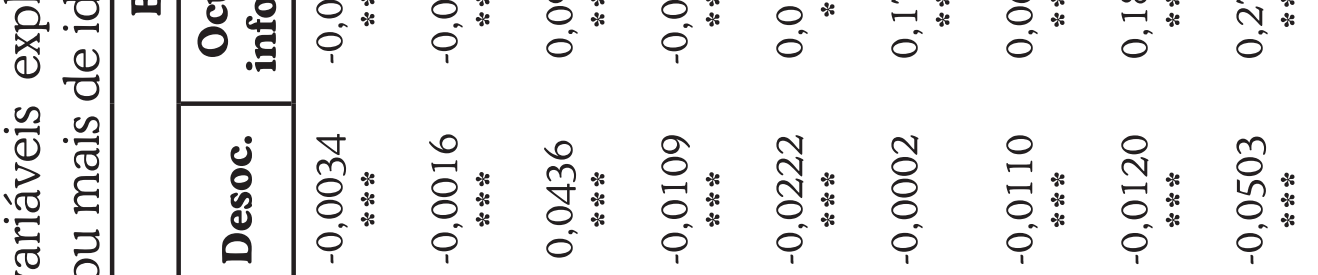

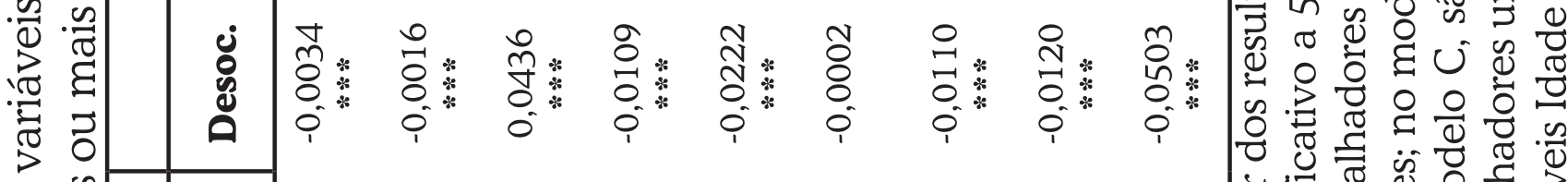

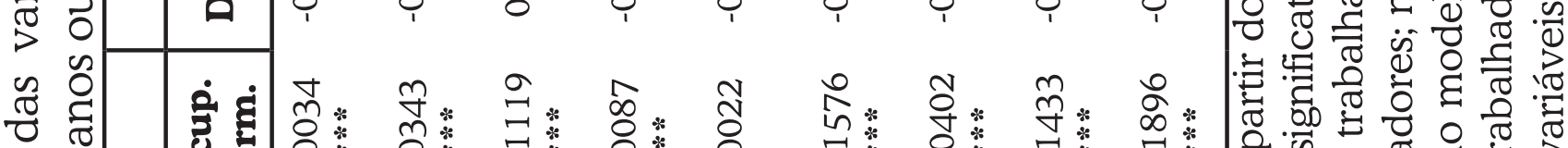

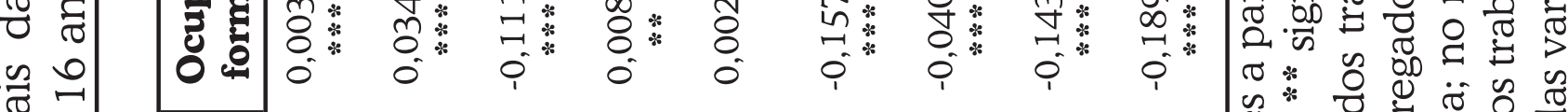

党学

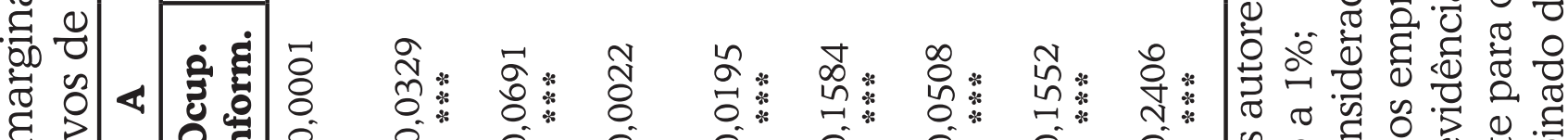

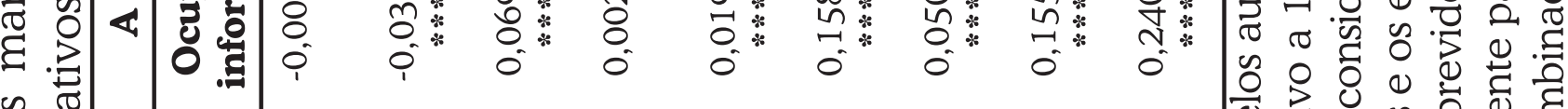

幽

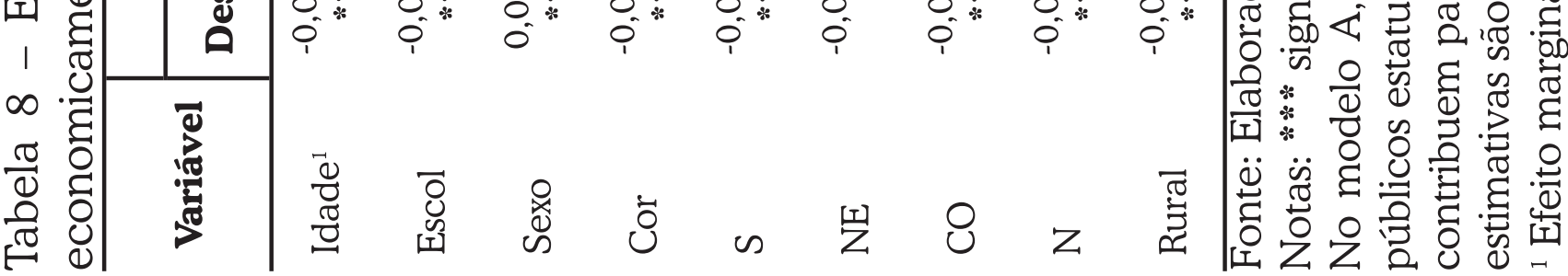


A variável que apresenta o maior impacto sobre a probabilidade de o indivíduo estar desocupado ou ocupado é Rural. As pessoas que residem no meio rural têm, em média, 5,1 pontos percentuais a menos de probabilidade de estar desocupadas em relação àquelas que moram no meio urbano (modelo A, Tabela 8). Além disso, residir no meio rural aumenta em 24,1 pontos percentuais a probabilidade de o indivíduo exercer uma ocupação informal e reduz em 19 pontos percentuais a de ele estar ocupado formalmente. Como ressaltado anteriormente, o menor nível de desemprego no campo pode, entre outras coisas, ser reflexo do êxodo rural ocorrido em anos recentes por conta do processo de mecanização, o qual levou a uma retração da oferta de trabalho no meio rural e, consequentemente, a uma redução do desemprego nesse meio e a um aumento do desemprego urbano.

A variável Idade apresenta efeito marginal negativo para a categoria Desocupado e positivo para a categoria Ocupado formalmente, indicando que os indivíduos mais velhos têm menor probabilidade de estar desocupados e maior de estar ocupados formalmente. Esse resultado se deve ao fato de as firmas privilegiarem, no ato da contratação, os trabalhadores mais experientes, principalmente aquelas que ofertam empregos formais. Observa-se, portanto, que as pessoas mais jovens, além de menores chances de conseguir um emprego, têm maior probabilidade de trabalhar informalmente.

Quanto maior a escolaridade do indivíduo, menor a probabilidade de ele estar desocupado ou ocupado informalmente. Cada ano completo de estudo aumenta em 3,4 pontos percentuais a probabilidade de a pessoa conseguir uma ocupação formal e reduz em 3,3 pontos percentuais a de ocupar-se informalmente. Esse resultado mostra a importância da qualificação na seleção dos indivíduos que ocupam os postos de trabalho de melhor qualidade e remuneração (empregos formais).

Se o indivíduo é do sexo feminino, a probabilidade de conseguir uma ocupação formal reduz-se em 11,2 pontos percentuais. Além disso, a probabilidade de as mulheres trabalharem informalmente e estarem desocupadas é, respectivamente, 6,9 e 4,3 pontos percentuais maior do que a dos homens. Quanto ao maior grau de informalidade entre as mulheres, há que se ressaltar o papel das atividades exercidas por elas. Há menos mulheres que homens trabalhando no setor indústria de transformação, no qual o grau de informalidade é baixo (34,7\%). Por outro lado, há mais mulheres que homens trabalhando nos setores alojamento e alimentação, serviços domésticos e outros serviços, nos quais o grau de informalidade é de $55,6 \%, 72,0 \%$ e $68,8 \%$, respectivamente. Não se pode ignorar, ainda, a questão do preconceito para explicar a predominância dos homens nos empregos de melhor qualidade e remuneração (formais) ou mesmo, a maior taxa de desocupação entre as mulheres.

Os resultados do modelo $\mathrm{A}$, na Tabela 8 , mostram, também, que os indivíduos brancos e amarelos têm menor probabilidade de estar desocupados e maior de estar ocupados formalmente que os indígenas, negros e pardos de mesma idade, escolaridade, sexo e local de residência. Isso demonstra que o preconceito racial ainda está presente no mercado de trabalho. 
A região onde a pessoa reside exerce influência considerável sobre sua condição de ocupação. Indivíduos que moram nas regiões Sul, Centro-Oeste e Norte têm menor probabilidade de estar desocupados do que os que residem no Sudeste. Depois de Rural, as variáveis com maior impacto sobre a probabilidade de o indivíduo estar ocupado informalmente são NE e N. Pessoas que residem nas regiões Nordeste e Norte têm, em média, 15,8 e 15,5 pontos percentuais a mais de probabilidade de estar ocupadas informalmente em relação àquelas que moram na região Sudeste. Conforme mostram os dados da PNAD (INSTITUTO BRASILEIRO DE GEOGRAFIA E ESTATÍSTICA, 2007), a parcela da população que trabalha com carteira de trabalho assinada nessas duas regiões é menor do que a das demais regiões brasileiras, ao passo que o percentual de indivíduos que trabalham por conta própria, na produção para o próprio consumo ou que são não remunerados é maior. Portanto, para fugir do desemprego, muitas pessoas no Nordeste e Norte se ocupam em trabalhos precários, informais.

Residir na região Centro-Oeste aumenta em 5,1 pontos percentuais a probabilidade de o indivíduo trabalhar informalmente e diminui em 4 pontos percentuais a de ele trabalhar formalmente em relação aos que moram no Sudeste. As pessoas que residem na região Sul têm probabilidade ligeiramente maior de estar ocupadas informalmente (1,9 ponto percentual) do que as que moram na região Sudeste.

A Tabela 8 apresenta, ainda, os efeitos marginais dos modelos B, C e D. Esses resultados servem, também, como um teste de robustez para aqueles do modelo A. Diferente do modelo A, os trabalhadores autônomos que residem no meio urbano e contribuem para a previdência são considerados formais no modelo B. Em geral, não há mudanças expressivas na magnitude ou no sinal dos efeitos marginais. O efeito marginal da variável Idade sobre a condição Ocupado informalmente passou a ser estatisticamente diferente de zero, apesar de ainda ser de pequena magnitude (cada ano a mais de idade diminui em 0,2 pontos percentuais a probabilidade de o indivíduo se ocupar informalmente). A variável Cor também passou a exercer efeito sobre a condição Ocupado informalmente e a magnitude de seu efeito sobre a condição Ocupado formalmente aumentou. Indivíduos brancos e amarelos têm 1,3 ponto percentual a menos de probabilidade de se ocupar informalmente e 2,4 pontos percentuais a mais de trabalhar formalmente.

$\mathrm{O}$ modelo $\mathrm{C}$ considera todos os trabalhadores segurados da previdência como pertencentes ao setor formal. Na região Sul, 16,8\% das pessoas ocupadas residem no meio rural, contra 7,5\% no Sudeste. Com isso, ao se incluir os pequenos produtores rurais na categoria Ocupados formalmente, os indivíduos que moram no Sul passaram a ter menor probabilidade de se ocupar informalmente (1,2 ponto percentual) e maior de conseguir uma ocupação formal (3,2 pontos percentuais) do que os que residem no Sudeste. Nas regiões Norte e Nordeste, onde também boa parcela da população ocupada vive no meio rural $(22,1 \%$ e $26,8 \%$, respectivamente), a probabilidade de as pessoas se ocuparem informalmente diminuiu em relação àquelas retradadas para os modelos $\mathrm{A}$ e $\mathrm{B}$, mas ainda continua alta (12,2 e 12,9 pontos percentuais, respectivamente). 
O resultado mais interessante diz respeito à variável Rural. Diferente dos resultados dos modelos $\mathrm{A}$ e $\mathrm{B}$, os do modelo $\mathrm{C}$ indicam que residir no meio rural diminui a probabilidade de o indivíduo trabalhar informalmente e aumenta a de trabalhar formalmente. No meio rural, 59,6\% dos trabalhadores ocupamse como autônomos $(27,1 \%)$, produtores para o próprio consumo $(16,1 \%)$, ou não remunerados (16,4\%). Ao se considerar esses trabalhadores como formais, o grau de informalidade no meio rural reduz-se drasticamente de 78,8\% para $19,4 \%$. Assim, a informalidade no meio rural torna-se menor do que a urbana, que é de $36,2 \%$. Com isso, os indivíduos que moram no meio rural passam a ter 29,2 pontos percentuais a menos de probabilidade de trabalhar informalmente e 35,1 pontos percentuais a mais de trabalhar formalmente em relação aos que residem nas áreas urbanas.

O modelo D é estimado apenas para os trabalhadores urbanos. São considerados formais todos aqueles trabalhadores urbanos segurados da previdência. Assim como nos modelos B e C, o efeito da idade sobre a probabilidade de estar ocupado informalmente é negativo e estatisticamente significativo. Os indivíduos da região Sul passaram a ter a mesma probabilidade de conseguir um emprego informal e, da mesma forma que no modelo $\mathrm{C}$, maior probabilidade de se ocupar formalmente do que os habitantes da região Sudeste. As pessoas da região Nordeste, em contrapartida, passaram a ter maior probabilidade de ficar desempregadas do que as do Sudeste, ressaltando a importância do meio rural na ocupação da população.

$\mathrm{O}$ fator que têm maior impacto sobre a probabilidade de o indivíduo se ocupar informalmente continua sendo residir nas regiões Nordeste e Norte. Isso mostra que a informalidade nessas regiões é alta tanto no meio rural, quanto no urbano. Na indústria de transformação, por exemplo, um setor conhecido como gerador de empregos mais formais, o grau de informalidade nas regiões Nordeste e Norte é de 54,3\% e 53,0\%, respectivamente, contra $28,8 \%$ na região Sudeste.

\section{Considerações Finais}

A informalidade se situa entre os principais problemas que atingem o mercado de trabalho brasileiro, constituindo-se em um obstáculo ao desenvolvimento do País. Diante disso, este artigo procurou identificar quais fatores exercem maior influência sobre a condição de ocupação de um indivíduo brasileiro economicamente ativo de 16 anos ou mais de idade. Para tal, utilizaram-se as informações da PNAD de 2007 e o modelo logit multinomial.

Observou-se que a probabilidade de o indivíduo estar desocupado decresce com a idade, ao mesmo tempo em que a de conseguir uma ocupação formal aumenta. Já existe uma proposta sendo analisada no Senado que prevê desconto no Imposto de Renda de empresas que contratarem jovens entre $18 \mathrm{e}$ 24 anos e adultos maiores de 50 anos. Além da concessão de incentivos fiscais para estimular a contratação de jovens, é necessário garantir que eles tenham suas carteiras de trabalho assinadas. Para isso, é preciso que se intensifique a 
fiscalização, principalmente junto às micro e pequenas empresas, pois são essas as que mais empregam os jovens. É necessário que se ampliem os programas de treinamento e estágio para estudantes, para que possam adquirir experiência e competir pelas vagas no mercado de trabalho.

Os resultados mostraram que quanto maior a escolaridade da pessoa, menor a chance de ela se ocupar informalmente. A probabilidade de estar desocupado também é menor para indivíduos com mais anos de estudo. A escolaridade tem servido para selecionar os indivíduos que ocuparão os postos formais de trabalho. Apesar disso, a educação pode ser utilizada para convencer a população dos benefícios da formalidade. Além do mais, cursos de treinamento e capacitação podem auxiliar trabalhadores autônomos a expandir seu negócio, viabilizando a formalização do mesmo.

Relativo aos homens, as mulheres têm maior probabilidade de estar desocupadas ou ocupadas informalmente. Indivíduos brancos ou amarelos têm menor probabilidade de estar desocupados e mais chances de conseguir uma ocupação formal do que indivíduos negros, pardos ou indígenas. Percebe-se, com isso, que o preconceito ainda persiste no mercado trabalho. O Ministério Público do Trabalho (MPT) lançou, em parceria com o IPEA, em abril de 2005, o programa Igualdade para Todos, que busca aumentar a admissão de negros e mulheres no mercado de trabalho, aproximar as médias salariais de brancos e negros e de homens e mulheres e criar critérios de ascensão profissional mais transparentes. O MPT investiga as empresas, elabora um perfil das desigualdades e institui um Termo de Ajustamento de Conduta (TAC) entre a empresa e o MPT, estabelecendo metas para os empregadores.

Com respeito às empregadas domésticas, alguns projetos visando incentivar a formalização foram recentemente aprovados no Senado, mas ainda precisam ser avaliados na Câmara. Um deles diminui para $6 \%$ a contribuição paga ao INSS pelo empregador (que hoje é de 12\%) e pela empregada (que atualmente é de $8 \%$ ). Outra proposta institui multa de $\mathrm{R} \$ 1$ mil a $\mathrm{R} \$ 10$ mil para o patrão que descumprir a lei. Se o empregado trabalhar sem registro, a multa ainda é acrescida em $50 \%$. Também foi aprovada a proposta que perdoa a dívida com o INSS do patrão que regularizar a situação da doméstica que trabalha sem registro. Outro projeto de lei que será votado na Câmara é o que define o número de dias de trabalho semanal a partir do qual a diarista passa a ser considerada empregada doméstica, tendo direito a carteira assinada.

Além da aprovação dos projetos citados, é necessário que se estimule o hábito de denunciar o preconceito e que este seja punido com maior rigor. Propagandas educativas nos meios de comunicação e debates nas escolas são importantes para criar uma conscientização contra o preconceito. É preciso incentivar e pressionar, judicial ou extrajudicialmente, as organizações públicas e privadas a implementar planos de correção das desigualdades de gênero e raça no mercado de trabalho. Se necessário, como uma ação emergencial, podem-se criar cotas no serviço público e dar incentivos fiscais às empresas para que contratem mais mulheres, negros, pardos e indígenas. 
Residir nas regiões Nordeste e Norte é um dos fatores que têm maior influência sobre a probabilidade de a pessoa trabalhar informalmente. Para fugir do desemprego, em torno de $40 \%$ das pessoas ocupadas nessas regiões trabalham por conta própria, produzem para o próprio consumo ou trabalham sem remuneração, contra cerca de $30 \%$ na média do Brasil. Além disso, mesmo em setores mais capitalistas, como a indústria de transformação, o grau de informalidade situa-se bem acima da média brasileira. Desse modo, o combate à informalidade nessas regiões passa, de um lado, por programas de financiamento e incentivos fiscais a empresas que não recolhem encargos trabalhistas ou não contribuem com a previdência por uma questão de sobrevivência. Por outro lado, deve-se intensificar a fiscalização e a penalização de empresas que se aproveitam da pobreza da população para não cumprir a legislação. Devemse criar, ainda, programas que estimulem o aumento do emprego assalariado (incentivos para a instalação de novas indústrias, por exemplo) para que a população tenha a opção de se ocupar em atividades de melhor qualidade.

A magnitude da informalidade no meio rural depende do conceito que se adota para defini-la. Se os pequenos agricultores são considerados formais, a informalidade no meio rural é menor do que nas áreas urbanas. Se forem considerados formais apenas aqueles trabalhadores ocupados em empreendimentos produtivos capitalistas, a informalidade no meio rural é quase o dobro da urbana.

De um modo geral, a redução da informalidade no Brasil passa pela ação do poder público, por intermédio da simplificação da legislação, da redução dos impostos (que tornam altos os custos da formalidade) e do convencimento da sociedade de que vale a pena ser formal.

\section{Referências}

CAMERON, A. C.; TRIVEDI, P. K. Microeconometrics: methods and applications. New York: Cambridge University Press, 2005. 1034 p.

CURI, A. Z.; MENEZES-FILHO, N. A. O mercado de trabalho brasileiro é segmentado? Alterações no perfil da informalidade e nos diferenciais de salários nas décadas de 1980 e 1990. Estudos Econômicos, São Paulo, v. 36, n. 4, out./dez. 2006.

DEDECCA, C. S.; BALTAR, P. E. A. Mercado de trabalho e informalidade nos anos 90. Estudos Econômicos, São Paulo, v. 27, n. especial, p. 65-84, 1997.

GREENE, W. H. Econometric analysis. 6. ed. New Jersey: Prentice Hall, 2008. 1178 p.

INSTITUTO BRASILEIRO DE GEOGRAFIA E ESTATÍSTICA. Pesquisa Nacional por Amostra de Domicílios (PNAD) 2007. Rio de Janeiro: IBGE, 2007.

INSTITUTO DE PESQUISA ECONÔMICA APLICADA. PNAD 2007: Primeiras análises mercado de trabalho, trabalho infantil e previdência. Comunicado da Presidência, n. 10, v. 2, set. 2008. 
MACHADO, A. F.; OLIVEIRA, A. M. H. C.; ANTIGO, M. Evolução do diferencial de rendimentos entre setor formal e informal no Brasil: o papel das características não observadas. Revista de Economia Contemporânea, Rio de Janeiro, v. 12, n. 2, p. 355-388, maio/ago. 2008.

MENEGUIN, F. B.; BUGARIN, M. S. A informalidade no mercado de trabalho e o impacto das instituições: uma análise sob a ótica da teoria dos jogos. Economia Aplicada, Ribeirão Preto, v. 12, n. 3, jul./set. 2008.

PERRY, G. E. et al. Informalidade: saída e exclusão. Washington: Banco Mundial, 2007.

RAMOS, L. O desempenho recente do mercado de trabalho brasileiro: tendências, fatos estilizados e padrões espaciais. IPEA, Rio de Janeiro, jan. 2007. (Texto para Discussão n. 1255)

RAMOS, L.; FERREIRA, V. Padrões espacial e setorial da evolução da informalidade no período 1991-2005. Pesquisa e Planejamento Econômico, v. 36, n. 3, p. 471-488, dez. 2006.

SILVA, P. L. N.; PESSOA, D. G. C.; LILA, M. F. Análise estatística de dados da PNAD: incorporando a estrutura do plano amostral. Ciência e Saúde Coletiva, Rio de Janeiro, v. 7, n. 4, p. 659-670, 2002.

STADUTO, J. A. R.; SHIKIDA, P. F. A.; BACHA, C. J. C. Alteração na composição da mão-deobra assalariada na agropecuária brasileira. Agricultura em São Paulo, São Paulo, v. 51, n. 2, p. 57-70, jul./dez. 2004.

SOUZA, A. M. Escolha de emprego e dualismo no mercado de trabalho. Pesquisa e Planejamento Econômico, Rio de Janeiro, v. 6, n. 1, p. 107-130, abr. 1976.

ULYSSEA, G. Informalidade no mercado de trabalho brasileiro: uma resenha da literatura. IPEA, 2005. (Texto para Discussão, n. 1070).

VAZ, F. M. Mudanças estruturais e mobilidade ocupacional no mercado de trabalho metropolitano no período 1982-2002. 2006. 171 f. Dissertação (Mestrado em Economia) - Universidade de Brasília, Brasília, 2006.

Recebido em: 29/10/2009.

Aceito em: 11/03/2011. 